\title{
Alat Pengisian Bensin Pada Penjual Besin Eceran Menggunakan Sistem Flow Sensor
}

\author{
Subandi ${ }^{1)}$, Prastiono Eko Pambudi ${ }^{2)}$, Gatot Santoso ${ }^{3)}$, Slamet Hani ${ }^{4)}$ \& Danang Ari Setyo Wibowo ${ }^{5)}$ \\ ${ }^{1,2,3,4,5}$ Institut Sains \& Tenologi Akprind Yoyakarta Alamat Jl. Kalisahak No. 28 Yogyakarta \\ Telp (0274) 563029, Fax (0274) 563847, Mobile 087839394478 \\ Website: www.akprind.ac.id, E-mail: subandi@akprind.ac.id, gatsan@akprind.ac.id
}

\begin{abstract}
Abstrak
Pada saat ini sering dijumpai penjual bensin eceran yang berada pada pinggiran jalan, baik di pinggir jalan raya hingga di jalan pedesaan. Memang mereka sangat membantu para pengendara bermotor disaat kendaraan yang mereka tumpangi terjadi masalah yaitu kehabisan bahan bakar. Namun pada saat membeli pada penjual bensin eceran, pasti sering merasa khawatir atas apa yang dijual para penjual bensin tersebut, yaitu takaran bensin yang mereka jual apakah sudah sesuai dengan takaran yang sebenarnya. Untuk mengurangi rasa khawatir tersebut, maka dibuatlah alat pengisian bensin eceran sesuai dengan takaran yang berfungsi untuk mengurangi rasa khawatir tersebut dengan menggunakan sistem flow sensor sebagai pendeteksi takaran yang tepat. Pengisian bensin menggunakan flow sensor ini meliputi rangkaian minimum sistem mikrokontroler ATMega8 sebagai unit kendali, rangkaian catu daya sebagai input, rangkaian driver motor, dan motor pompa sebagai output. Alat pengisian bensin eceren ini memiliki keakuratan flow sensornya sudah optimal, karena dari 5 kali percobaan untuk volume 1 liter bensin maka rata-rata error yang didapat hanya 1,6 detik.
\end{abstract}

Kata kunci: aliran sensor, sensor hall effect, mikrokontroler ATMega8

\begin{abstract}
At this time, retail gasoline sellers are often found on the side of the road, both on the side of the highway to the rural road. Indeed, they are very helpful for motorists when the vehicle they are riding in occurs a problem, namely running out of fuel. However, when buying from a retail gasoline seller, you are often worried about what the gasoline sellers are selling, namely whether the amount of gasoline they sell is in accordance with the actual quantity. To reduce this worry, a retail petrol filling device was made according to the dosage which functions to reduce the worry by using a flow sensor system as a detection of the correct dose. Filling gasoline using this flow sensor includes a minimum series of the ATMega8 microcontroller system as a control unit, a power supply circuit as input, a motor driver circuit, and a pump motor as output. This cool petrol filling tool has optimal flow sensor accuracy, because from 5 trials for the volume of 1 liter of gasoline, the average error obtained is only 1.6 seconds.
\end{abstract}

Keywords: flow sensors, hall effect sensors, microcontroller ATMega8

\section{PENDAHULUAN}

Kemajuan di bidang elektronika semakin hari semakin pesat dan manusia akan terus berusaha untuk selalu membuat peralatan elektronika yang lebih sempurna untuk memenuhi kebutuhan, meningkatkan kesejahteraan, dan untuk membantu mempermudah pekerjaan manusia tersebut. Peralatan elektronika baik dari yang sederhana maupun yang rumit sudah banyak dikembangkan untuk lebih mempermudah pekerjaan manusia. Perkembangan teknologi saat ini telah merambah ke segala aspek kehidupan sehingga saat ini seolah dimanjakan oleh adanya alat-alat yang dapat memberikan kemudahan.

Pada saat ini sering kita temui penjual bensin premium eceran yang berada pada pinggiran jalan, baik di pinggir jalan raya hingga di jalan pedesaanpun kita dapat menjumpai penjual bensin premium eceran. Dengan berkembangnya teknologi saat ini, penjual bensin eceran saat ini dapat memanfaatkan sistem kerja dari flow sensor yang pada penakaran bensinnya dapat meminimalisir terjadinya kesalahan pengukuran seperti yang dilakukan penjual bensin eceran saat ini yang hanya memakai wadah untuk menuang bensin tanpa tahu banyaknya kapasitas dalam wadah tersebut.

Dengan menggunakan sistem flow sensor ini, maka kesalahan penakaran bensin tersebut dapat diminimalisir sekecil mungkin, karena pada flow sensor ini mempunyai half effect, dimana output half effect ini akan sebanding dengan pulsa yang dihubungkan dengan rotor.

\section{LANDASAN TEORI}

DOI: 10.22236/teknoka.v5i.339 
Pengembangan model berbasis mikrokontroler dengan sistem pengontrol aliran air telah dilakukan. Dalam sistem ini, sebagai pendeteksi dengan photodioda dan sebagai sensor yang dijadikan input frekuensi mikrokontroler. Sinyal ini diubah menjadi laju aliran dengan menggunakan Person In Charge (PIC).

Pengembangan sebuah sensor diferensial dengan tekanan aliran zat cair pada pipa lurus. Dalam sistem ini perbedaan tekanan antara pipa masukkan dan pipa keluaran dapat terdeteksi dan diubah menjadi sinyal tegangan oleh sensor diferensial. Sinyal tegangan ini ditransmisikan ke mikroprosesor untuk menentukan laju aliran zat cair.

Penggunaan teknik pengukuran aliran dengan menggunakan ultrasonic flow meter dengan mengoptimalkan jaringan syaraf. Tujuannya adalah untuk memperluas jangkauan linearitas pengukuran hingga $100 \%$ dari masukkan, untuk membuat sistem pengukuran adaptif terhadap berbagai diameter pipa, identitas cairan, dan temperatur cairan.

Perancangan yang terkait dengan pengisian bahan bakar telah banyak dilakukan diantaranya mengenai pembuatan suatu prototipe Stasiun Pengisian Bahan Bakar Umum (SPBU) yang berbentuk mini menggunakan mikrokontroler ATMega8535 yang volume keluarannya didasarkan pada nilai masukan dalam satuan rupiah. Mikrokontroler ATMega8535 digunakan sebagai pengolah counter, pembanding jumlah volume masukan dengan volume keluaran, penyimpan data, dan pengaktif relay. Persentase kesalahan takaran SPBU-Mini sebesar 6\% [1].

Penelitian yang memanfaatkan LabView, tentang estimasi waktu tangki harian yang terkuras dan diisikan kembali, sebagai simulasi pengawasan sehingga memudahkan kinerja operator. Pemodelan yang berdasarkan karakteristik mesin utama, generator, tangki harian, serta pompa sebagai input parameter dalam menjalankan simulasi [2].

Penelitian yang berkaitan dengan menganalisis proses datangannya pelanggan, waktu pelayanan pelanggan dan menentukan model yang sesuai pada SPBU PT. Fikri Darmawan Kabupaten Melawi. Pada SPBU PT Fikri Darmawan Kabupaten Melawi, pada tahap pengisian bahan bakar setelah dilakukan uji ChiSquare diperoleh proses kedatangan berdistribusi General (dinotasikan dengan $G$ ) dan waktu pelayanan juga berdistribusi General (dinotasikan dengan $G$ ). Disiplin antrian adalah FIFO (First In First Out) dengan satu fasilitas pelayanan. Ukuran dalam antrian tidak terbatas dinotasikan $\infty$. Tidak ada batasan untuk ukuran sumber pemanggilan dinotasikan $\infty$ (tidak terbatas). Model antrian yang sesuai pada SPBU PT. Fikri Darmawan Kabupaten Melawi yaitu dengan menggunakan suatu model antrian $(\mathrm{G} / \mathrm{G} / 1):(\mathrm{FIFO} / \infty / \infty$ /tidak terbatas) [3].

Perancangan sistem untuk pembelian bahan bakar minyak menggunakan Radio Frequency Identification (RFID), dimana sistem mampu mengontrol jumlah pembelian menurut saldo yang tersedia, mengingat dalam prosesnya konsumen akan melakukan pembelian bahan bakar minyak secara mandiri tanpa ada petugas di SPBU [4].

Simulasi pada alat pengukur BBM sesuai takaran atau volume isi tangki kendaraan bermotor dalam bentuk prototipe, dimana dibuat hanya untuk tujuan penelitian saja. Sedangkan alat yang digunakan adalah Water Sensor Flow yang mengendalikannya adalah Arduino Uno dan informasinya dalam Liquid Crystal Display (LCD) [5].

Pengisian pada tangki BBM dan memonitoring suhu sudah dapat dilakukan secara otomatis yang memanfaatkan PLC Omron tipe CP1E N20DR-D 20 I/O dengan program ladder diagram yang dirancang menggunakan aplikasi komputer $C X$-Programmer [6].

\section{Water Flow Sensor}

Water flow sensor terdiri dari tubuh katup plastik, rotor air, dan sebuah sensor hall efect. Ketika air mengalir melalui pipa dalam sensor ini, maka akan mengenai gulungan-gulungan rotor dan membuatnya berputar. Kecepatan putar rotor akan berubah ketika aliran air berubah pula. Output dari sensor hall-effect akan sebanding dengan pulsa yang digenerate oleh rotor. Kelebihan dari sensor ini adalah hanya membutuhkan 1 sinyal (SIG) selain jalur 5V DC dan ground.

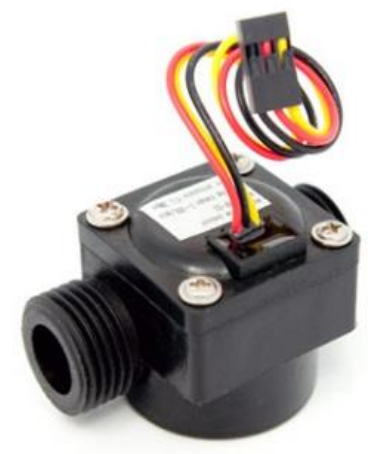

Gambar 1 Water Flow Sensor G1/2

Perangkat elektronika dapat dipicu menggunakan 2 sumber listrik, yaitu listrik arus searah, dan listrik arus bolak balik tergantukng dengan pemakaian beban perangkat tersebut. Untuk catu daya yang sering digunakan pada perangkat elektronika adalah catu daya jenis arus searah Direct Current (DC), karena kebanyakan dari rangkaian elektronika tidak membutuhkan beban yang terlalu besar.

Seminar Nasional TEKNOKA ke - 5, Vol. 5, 2020 ISSN No. 2502-8782 
Untuk catu daya jenis DC sendiri dapat menggunakan baterai Lithium Poliner (Li-Po) yang besar tegangannya sesuai dengan perangkat elektronika pada umumnya.

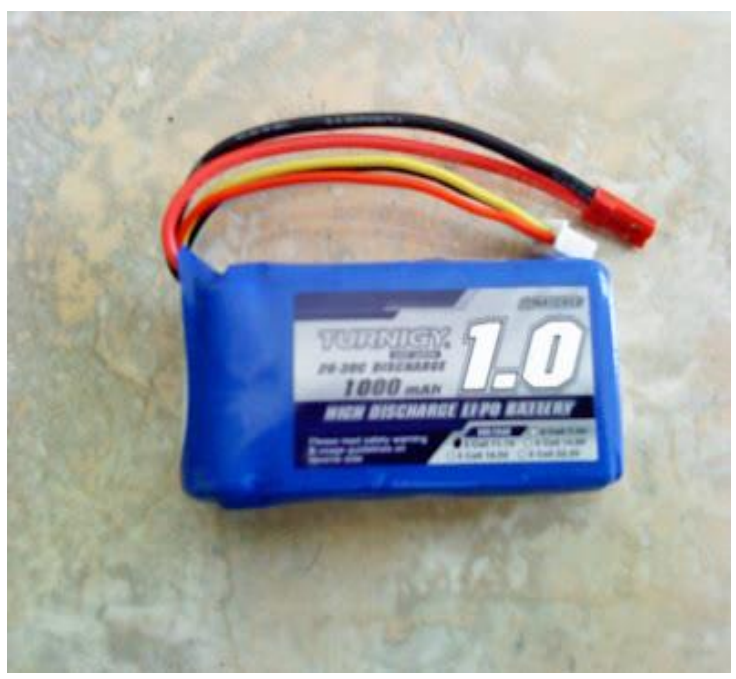

Gambar 2 Catu daya jenis Li-Po

Fitur-fitur yang dimiliki ATMega8 antara lain:

1. Flash memory sebesar 8 Kbytes untuk memori progam.

2. Memori data (SRAM) sebanyak 608 alamat memori data yang terbagi menjadi 3 bagian, yaitu 32 buah register file, 64 buah IO register, dan 512 byte internal SRAM.

3. Memori data EEPROM 8 bit sebesar 512 byte $(\$ 000$ - \$1FF).

4. Saluran I/O sebanyak 23 buah, yaitu port $\mathrm{B}$, port $\mathrm{C}$, dan port $\mathrm{D}$.

5. Unit interupsi internal dan eksternal.

6. Port USART untuk komunikasi serial.

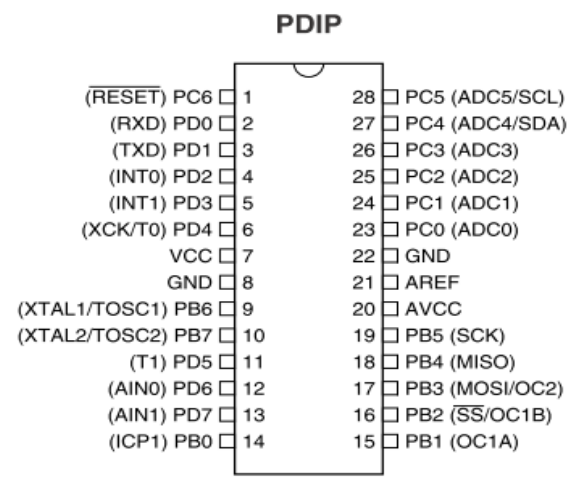

Gambar 3 Konfigurasi pin ATMega8

Electric water pump adalah pompa yang digunakan untuk memompa air pada galon yang cara pemakaiannya hanya dengan menekan saklar yang terdapat pada pompa tersebut. Electric water pump ini termasuk kedalam motor DC yang bekerja berdasarkan hukum ampere dan hukum Lorentz, yaitu:

Copyright (C) 2020 FT-UHAMKA. - All rights reserved DOI: 10.22236/teknoka.v5i.339
1. Di sekitar penghantar yang dialiri arus listrik akan timbul medan magnet.

2. Suatu penghantar yang dialiri arus listrik jika berada pada medan magnet akan mengalami suatu gaya yang disebut gaya Lorentz.

Motor DC yang digunakan adalah motor DC 3 volt, untuk mendapatkan gerakan yang cepat dan kuat maka diperlukan suatu penggerak motor DC yang mana mempunyai spesifikasi untuk menjalankan motor tersebut.

Pada rangkaian driver motor DC ini digunakan transistor TIP31 yang dirangkai secara darlington. Tujuan transistor ini dirangkai secara darlington adalah untuk memberikan arus yang besar, karena motor pompa yang digunakan sendiri membutuhkan arus yang lumayan besar agar pompa dapat bekerja secara optimal.

LCD adalah suatu jenis media tampil yang menggunakan kristal cair sebagai penampil utama. LCD sudah digunakan diberbagai bidang, misalnya alat-alat elektronik seperti televisi, kalkulator dan lain sebagainya. LCD yang khusus hanya untuk menampilkan tulisan disebut LCD karakter. Sedangkan biasanya disebutkan jumlah kolom dan barisnya misalnya $16 \times 2$, yang berarti terdapat 16 kolom dan 2 baris.

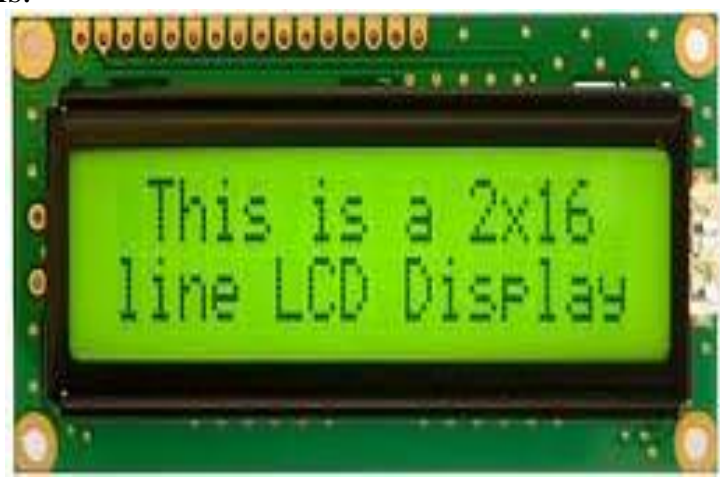

Gambar 4 LCD $16 \times 2$

\section{METODOLOGI PENELITIAN}

\section{Alat dan bahan \\ Alat}

Diperlukan beberapa peralatan yang akan digunkan untuk mendukung perancangan alat ini, diantaranya sebagai berikut:

1. Multimeter digital

2. Osciloscope

3. Solder

4. Gergaji besi

5. Tang potong

6. Bor listrik

\section{Bahan}


Beberapa bahan yang diperlukan untuk keberhasilan perancangan alat ini adalah sebagai berikut:

1. Galon air minum sebagai penampung bensin.

2. Electric water pump sebagai motor pompa untuk memompa bensin.

3. Pipa PVC $1 / 2$ sebagai penyalur bensin.

4. Penampil berupa LCD untuk menampilkan petunjuk pengunaan alat dan penunjuk aktifitas kerja alat.

5. Mikrokontroler ATMega8 sebagai komponen kendali utama keseluruhan sistem alat yang dirancang.

6. Baterai Li-Po sebagai supply utama dalam alat.

7. Transistor TIP31 sebagai driver motor.

8. Flow sensor sebagai sensor input-an bensin ke dalam botol.

\section{Tahapan Perancangan}

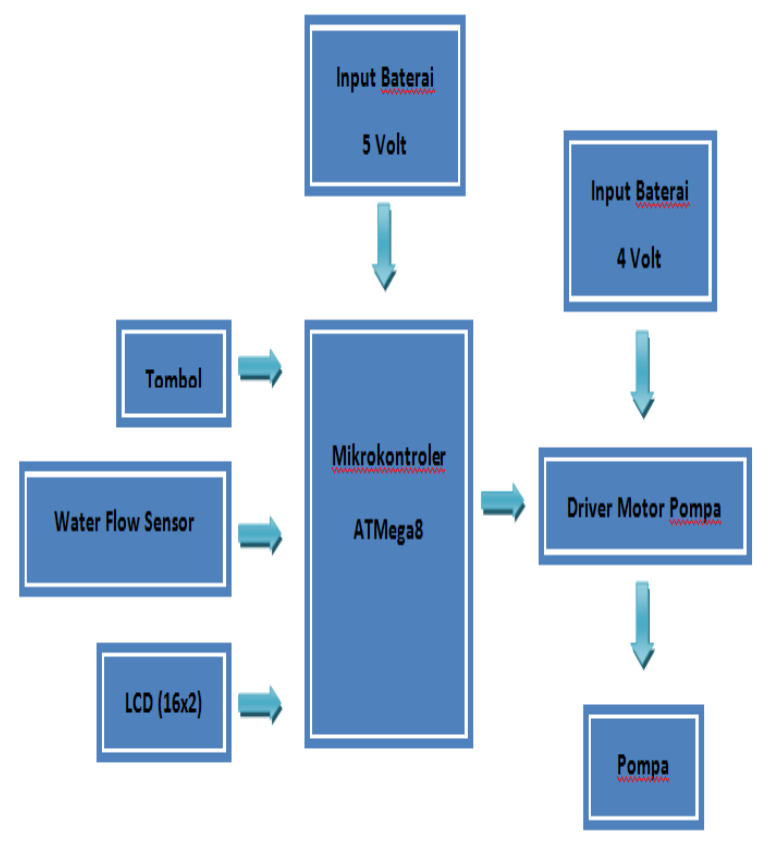

Gambar 5 Blok diagram rangkaian keseluruhan

Perancangan sistem pengisian bensin dengan flow sensor ini tersusun dari beberapa blok rangkaian, yaitu mikrokontroler sebagai pengendali, baterai sebagai catu daya, flow sensor sebagai penghitung aliran, dan motor pompa sebagai pemompa bensin dalam wadah.

Terdapat 2 jenis catu daya di rangkaian ini, dikarenakan driver motor hanya membutuhkan catu daya yang lebih kecil dibandingkan dengan catu daya mikrokontroler agar motor pompa dapat berputar dengan optimal.

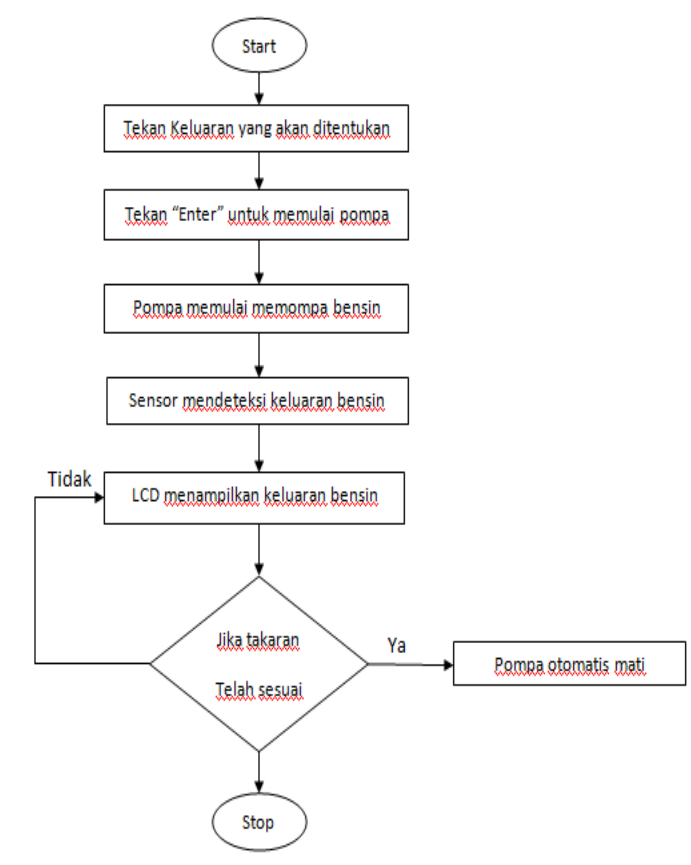

Gambar 6 Flowchart sistem flow sensor

Pada saat bensin melewati sensor maka akan dibaca oleh rotor yang terdapat dalam sensor tersebut, kecepatan rotor sendiri dapat berubah sesuai dengan kecepatan laju bensin yang melewatinya. Setiap bensin yang melalui rotor akan diubah menjadi medan magnet oleh sensor hall yang kemudian akan menghasilkan keluaran frekuensi yang kemudian dikirim menuju mikrokontroler.

\section{a. Perancangan rangkaian \\ Rangkaian pengendali utama}

Rangkaian pengendali utama terdiri dari sebuah chip mikrokontroler ATMega8 yang didalamnya terdapat instruksi-instruksi yang terangkai untuk melakukan pengendalian terhadap peralatan yang terhubung. Progam yang telah dibuat pada komputer diisikan ke dalam mikrokontroler melalui koneksi MOSI (port PB.3) yang berfungsi untuk mengirimkan data serial yang akan ditulis pada flash/EEPROM, MISO (port PB.4) berfungsi untuk konfirmasi data yang dikirimkan apakah mengalami kegagalan kirim atau tidak, sedangkan SCK (port PB.5) adalah sinchronus clock, detak sinkronasi atau untuk mengatur clock pada saai pengisian IC mikrokontroler. Mikrokontroler ATMega8 memiliki oscillator on-chip internal, yang dapat digunakan sebagai sumber detak (clock) ke CPU atau sebagai penghasil detak untuk mikrokontroler. 


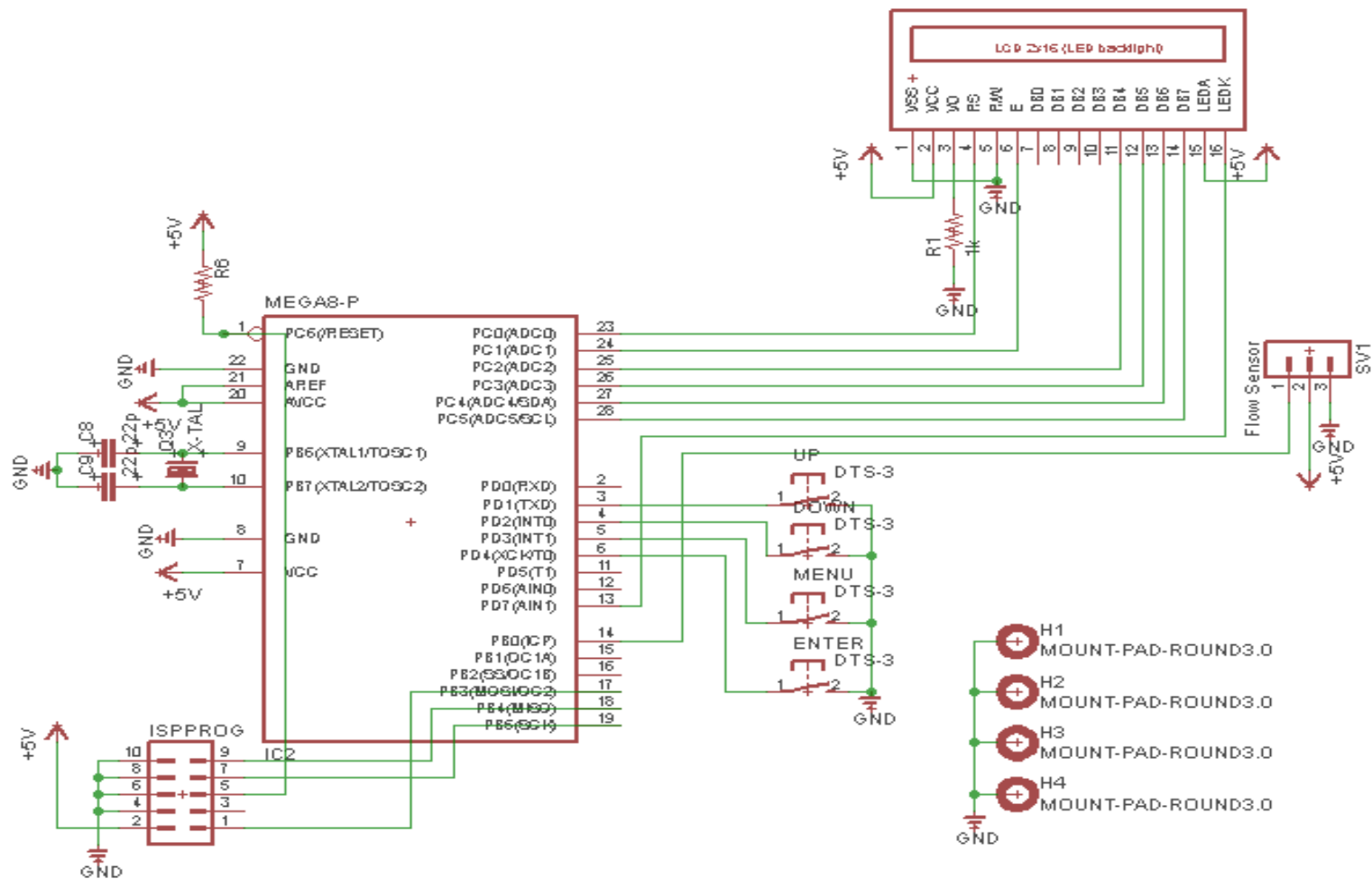

Gambar 7 Rangkaian pengendali utama

a. Flow sensor yang berfungsi sebagai input untuk mengetahui keluaran debit air yang nantinya akan dikirimkan kedalam mikrokontroler ATMega8.

b. 4 buah tombol yang berfungsi sebagai kendali banyaknya takaran yang akan digunakan.

c. Konektor yang berfungsi untuk mengirimkan progam kedalam mikrokontroler ATMega8.

\section{Bagian output}

LCD yang berfungsi sebagi penampil data dari keluaran air dari flow sensor. Mikrokontroler mengirimkan data ke LCD untuk kemudian diterjemahkan, selanjutnya data tersebut akan membangkitkan karakter yang ada didalam CGROM (Character Generator ROM), sehingga karakter dapat ditampilkan pada layar LCD. Sambungan control display terletak pada pin RS, RW dan E, yang berfungsi sebagai scaning untuk mengendalikan display (penampil). Counter LCD terletak pada pin D4-D7, yang berfungsi untuk mencacah atau menampilkan instruksi perintah dari mikrokontroler berupa angka atau huruf pada LCD.

\section{Rangkaian driver}

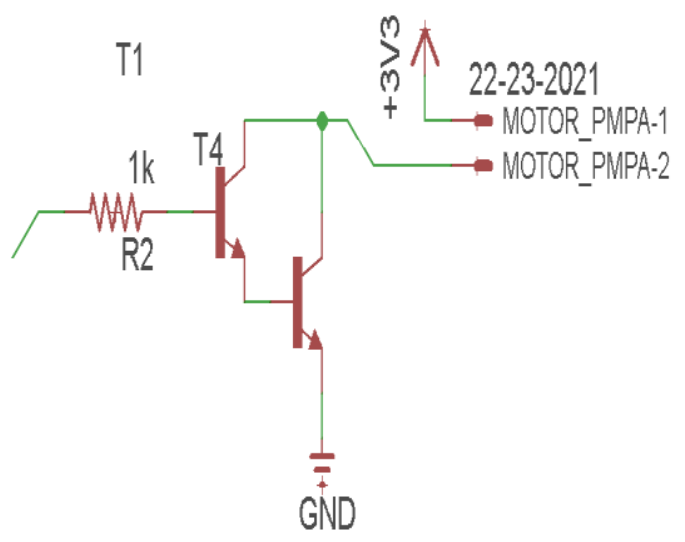

Gambar 8 Rangkain driver water pump

Pada rangkaian driver, dapat dilihat bahwa driver tersebut menggunakan transistor TIP31 yang dirangkai secara Darlington. Hal ini disebabkan karena motor yang digunakan membutuhkan arus yang cukup besar. Oleh karena itu rangkaian driver dirangkai secara Darlington, karena transistor TIP31 yang dirangkai secara Darlington akan menghasilkan arus yang cukup besar.

\section{Rangkaian power supply}

Pada rangkaian power supply menggunakan komponen IC regulator 7805 yang dapat diperlihatkan pada gambar 9 . 


\section{Ukuran papan PCB.}

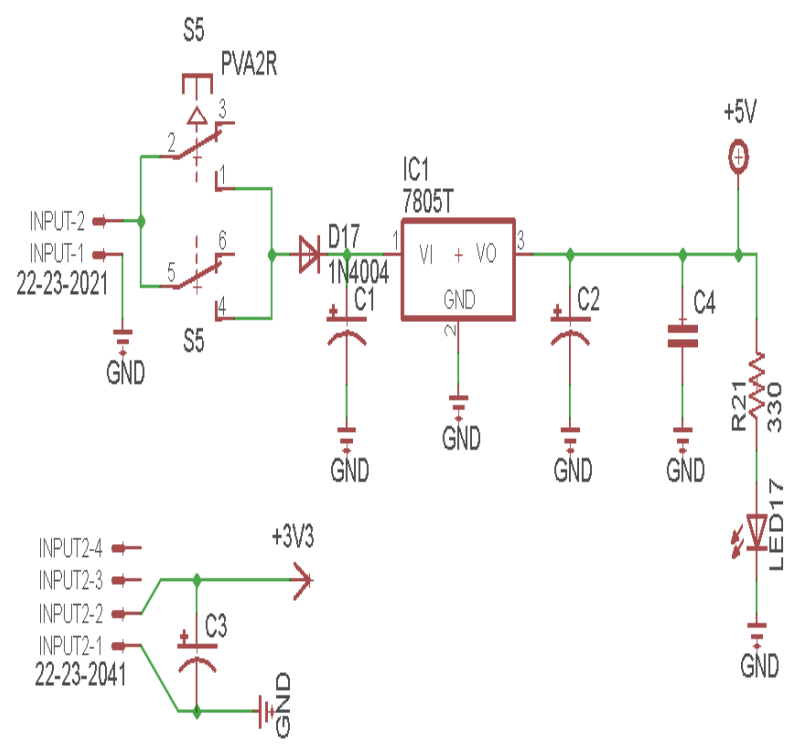

Gambar 9 Rangkaian power supply

IC regulator 7805 berfungsi sebagai regulator yang menghasilkan tegangan 5 volt. Keluaran IC tersebut diseri menggunakan kapasitor ke ground yang berfungsi sebagai penghilang noise pada masukkan Aref. Kemudian kapasitor dihubungkan pada pin Aref yang berfungsi sebagai tegangan referensi ADC.

Mikrokontroler ATMega8 dan motor memerlukan supply yang berbeda, yaitu 3-4 V untuk motor pompa, dan 4,5-5,5 V untuk ATMega8.

a. Supply $3 \mathrm{~V}$ sendiri menggunakan supply langsung dari baterai Li-Po yang terdapat tegangan 3-4 V.

b. Supply $5 \mathrm{~V}$ sendiri menggunakan IC 7805 yang dapat mengubah tegangan menjadi $5 \mathrm{~V}$.

\section{a. Perancangan perangkat keras (hardware)}

Perancangan hardware meliputi pembahasan penggambaran pola jalur Printed Circuit Board (PCB) dengan menggunakan komputer, proses pembuatan PCB, serta pembahasan perakitan rangkaian.

\section{b. Perancangan mekanik}

Setelah perancangan elektronik selesai, dilanjutkan pada proses perancangan mekanik. Yang pertama kali dilakukan adalah proses perancangan mekanik yaitu saluran pipa penyalur bensin. Proses pembuatan saluran bensin ini meliputi pengukuran panjang pipa, pemberian tanda, pemotongan pipa dan penempelan setiap pipa.

Didalam pembuatan saluran bensin ini, ada beberapa hal yang perlu diperhatikan sebelum perencanaan dimulai. Hal ini bertujuan untuk memudahkan dalam melakukan proses pengontrolan, serta pengoperasian alat nantinya, yaitu:

1. Ukuran komponen

\section{c. Perancangan perangkat lunak (software)}

Dalam perancangan perangkat lunak ini ada beberapa tahapan yang dilalui berkaitan dengan pemrograman. Untuk memudahkan pembahasan perancangan perangkat lunak ini, pembahasan dibagi menjadi beberapa hal yang meliputi pembahasan dasar pemrograman bahasa dasar (BASCOM), pemrograman dengan compiler BASCOM-AVR, dan pemrograman alat.

Ada banyak cara untuk menuliskan progam ke mikrokontroler, salah satunya adalah menggunakan bahasa dasar. Alasan penggunaan bahasa ini adalah kemudahan dalam pemahaman pemrogaman dan jika menggunakan compiler BASCOM AVR maka akan terasa lebih mudah karena telah dilengkapi dengan simulator.

\section{Prosedur pengambilan data hasil percobaan}

Diadakannya prosedur pengambilan data hasil percobaan karena agar data hasil yang diperoleh nantinya sesuai dengan yang diinginkan dari perancangan ini.

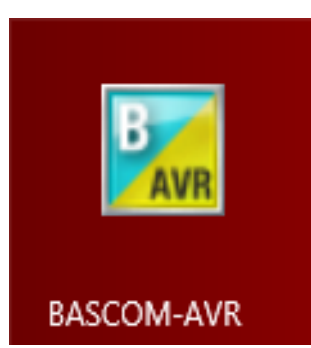

Gambar 10 Icon BASCOM AVR

\section{Pemrogaman alat}

Pemrograman alat terbagi menjadi beberapa blok sistem yang di program seperti pengalamatan pada mikrokontoler, LCD, tombol, dan flow sensor.

\section{Pengalamatan progam pada LCD}

Program ini untuk mengenali atau mengidentifikasi mikrikontroler dan kristal yang digunakan. Kemudian program mengalamatkan fungsi-fungsi pin pada mikrokontroler, yang terkoneksi dengan device lain seperti tombol, LCD, pompa motor dan sensor flow. Sehingga diketahui fungsi masing-masing pin, sehingga ketika device yang terkoneksi ingin diaktifkan maka program selanjutnya hanya memberi instruksi sesuai yang diinginkan.

\section{Pemrograman LCD}

Ada dua metode untuk menghubungkan LCD ke mikrokontroler, yaitu yang pertama dengan langsung 
menghubungkan dengan port mikrokontroler (pin mode), yang kedua dengan menghubungkan LCD dengan bus data, hal ini dilakukan jika rangkaian terhubung dengan RAM eksternal. Pada perancangan alat ini metode sambungan LCD yang digunakan adalah dengan metode pin mode.

\section{Pemrograman tombol}

Pemrograman tombol yaitu pemrogaman untuk memberikan instruksi pada mikrokontroler. Kemudian dialamatkan data-data yang diperlukan untuk logika kerja sesuai yang ditekan oleh tombol, sehingga ketika ada instruksi dari mikrokontroler untuk mengaktifkan motor dan flow sensor maka data cukup menekan tombol sesuai subrutin yang dibuat pada program, sehingga tidak terlalu banyak membuat perintah pada penulisan program.

\section{Pemrograman flow sensor}

Pemrograman flow sensor adalah pemrograman untuk "indikasi" mengaktifkan flow sensor dengan nilai frekuensi tertentu yang dapat dikalibrasi.

\section{Prosedur pengambilan data hasil percobaan}

Diadakannya prosedur pengambilan data hasil percobaan karena agar data hasil yang diperoleh nantinya sesuai dengan yang diinginkan dari perancangan ini.

Pada dasarnya didalam perencanaan dan pembuatan alat untuk mengetahui apakah alat tersebut sudah bekerja dengan baik atau belum, diperlukan pengujian dan pengukuran pada masing-masing bagian. Sehingga dari hasil pengukuran dan pengujian tadi dapat diketahui kemampuan dan batas penggunaan alat seperti sistem yang dikehendaki alat tersebut.

Sebelum melakukan pengujian perlu diperhatikan bahwa alat-alat yang telah dipersiapkan harus dirangkaikan dengan alat yang akan diuji sesuai dengan prosedur yang telah disiapkan, dan perlu diperhatikan batas ukur dari alat ukur harus sesuai dengan nilai atau batas pada alat ukur tersebut. Setelah yakin dengan rangkaian tersebut maka pengukuran alat dapat segera dilakukan.

Semua pengukuran yang dilakukan menggunakan kristal dengan kondisi baik, jadi dari percobaan yang dilakukan dapat diketahui efek dari kelayakan kristal yang bekerja pada rangkaian elektronika.

\section{HASIL DAN PEMBAHASAN}

Setelah perancangan selesai secara keseluruhan, maka dilakukan pengujian alat untuk mengetahui bagaimana akurasi dari kerja alat secara keseluruhan dan keterkaitan kinerja terhadap sistem didalamnya. Pengambilan data secara langsung pada alat yang telah selesai diuji, yang dilakukan di Laboratorium Institut Sains \& Teknologi AKPRIND Yogyakarta.

\section{a. Pengujian catu daya}

Dalam uji coba power supply terdapat dua jenis pengujian untuk melihat output pada sistem tersebut. Pengujian ini bertujuan untuk memberikan input ke sensor flow dan electric motor pump hingga mendapat input yang tegangannya dianggap optimal sesuai dengan yang diinginkan. Pengujian ini sendiri terdiri dari:

1. Pengujian output 3 volt,

2. Pengujian output 5 volt.

\section{b. Pengujian output $3 \mathrm{~V}$}

Untuk pengujian output $3 \mathrm{~V}$ sendiri langsung menggunakan baterai Li-Po yang didalamnya terdapat bermacam-macam keluaran tegangan, diantaranya keluaran sebesar $4 \mathrm{~V}$.

Keluaran $3 \mathrm{~V}$ nantinya akan masuk kedalam motor pompa yang membutuhkan tegangan $3 \mathrm{~V}$ hingga $4 \mathrm{~V}$ agar motor pompa dapat bekerja secara optimal.

\section{c. Pengujian output $5 \mathrm{~V}$}

Untuk pengujian output $5 \mathrm{~V}$ yaitu menggunakan LM 7805 yang menghasilkan keluaran $5 \mathrm{~V}$ yang dimana untuk LCD sendiri mengguanakan tegangan sebesar 5 V. Tegangan yang terpangkas bisa dihitung menggunakan rumus:

$$
V_{\text {dadal }}=V_{\text {input }}-V_{\text {output }}
$$

Sehingga dapat dicari tegangan dadal atau tegangan yang terpangkas.

Tabel 1 Nilai Tegangan dadal LM 7805

\begin{tabular}{|c|c|c|c|}
\hline No. & $\begin{array}{c}\text { Tegangan } \\
\text { Input } \\
\text { Baterai } \\
\text { ( Volt) }\end{array}$ & $\begin{array}{c}\text { Tegangan } \\
\text { Output dari } \\
\text { Regulator } \\
\text { ( Volt })\end{array}$ & $\begin{array}{c}\text { Tegangan } \\
\text { Dadal 7805 } \\
\text { ( Volt ) }\end{array}$ \\
\hline 1 & 11,45 & 4,97 & 6,48 \\
\hline 2 & 11,46 & 4,96 & 6,5 \\
\hline 3 & 11,46 & 4,96 & 6,5 \\
\hline 4 & 12,13 & 4,96 & 7,17 \\
\hline 5 & 12,13 & 4,96 & 6,76 \\
\hline \multicolumn{2}{|c}{ Rata - rata } \\
\hline
\end{tabular}

Tegangan dadal LM 7805 pada beberapa pengujian mendapatkan rata-rata tegangan dadalnya 6,76 V. Nilai ini masih berada pada jangkauan IC regulator 7805 sehingga power supply tidak ada masalah.

\section{d. Pengujian driver motor}


Untuk pengujian driver sendiri menggunakan transistor jenis NPN dengan tipe TIP31. Transistor tipe TIP31 sendiri adalah transistor yang mampu menguatkan arus, karena motor pompa yang dipakai membutuhkan arus yang besar.

Tabel 2 Keluaran transistor NPN TIP31

\begin{tabular}{|c|c|c|}
\hline No & $\begin{array}{c}\text { Masukkan TIP31 } \\
\text { (Volt) }\end{array}$ & $\begin{array}{c}\text { Keluaran TIP31 } \\
\text { (Volt) }\end{array}$ \\
\hline 1 & 1,28 & 3,27 \\
\hline 2 & 1,28 & 3,21 \\
\hline 3 & 1,29 & 3,21 \\
\hline 4 & 1,30 & 3,22 \\
\hline 5 & 1,32 & 3,24 \\
\hline \multicolumn{2}{|c|}{ Rata-rata } & 3,23 \\
\hline
\end{tabular}

Dari keluaran rata-rata transistor TIP31 sebesar 3,23 $\mathrm{V}$, yang masih berada dalam jangkauan motor pompa yang membutuhkan tegangan sebesar $3 \mathrm{~V}$ hingga $4 \mathrm{~V}$ agar dapat bekerja secara optimal.

\section{e. Pengujian aliran pada flow sensor}

Pada flow sensor, terdapat rumus untuk mencari banyaknya volume cairan yang yang melaju melewati flow sensor, rumus tersebut dapat digunakan untuk mencari volume zat cair yang akan kita cari nantinya.

Untuk menghitung banyaknya volume yang keluar, maka digunakan rumus:

Dimana:

$$
\mathrm{Q}=\mathrm{f} / 7,5
$$

$$
\begin{aligned}
\mathrm{Q}= & \text { banyaknya volume zat cair yang } \\
& \text { melalui flow sensor (liter/menit) } \\
f= & \text { frekuensi }(\mathrm{Hz}) \\
7,5= & \text { konstanta }
\end{aligned}
$$

Untuk pengujian frekuensi sendiri dilakukan beberapa kali percobaan untuk mendapatkan nilai frekuensi dari flow sensor itu sendiri. Rata-rata frekuensi dari flow sensor yang menggunakan pompa galon adalah sebesar $31,8 \mathrm{~Hz}$, yang nantinya data tersebut akan sebagai patokan untuk mencari banyaknya volume zat cair yang melewati flow sensor.

Tabel 3 Tabel keluaran frekuensi flow sensor

\begin{tabular}{|c|c|}
\hline Percobaan ke- & Frekuensi (Hz) \\
\hline 1 & 31,5 \\
\hline 2 & 32 \\
\hline 3 & 31 \\
\hline 4 & 32 \\
\hline 5 & 32,5 \\
\hline Rata-rata & 31,8 \\
\hline
\end{tabular}

Copyright $(2020$ FT-UHAMKA. - All rights reserved DOI: 10.22236/teknoka.v5i.339
Dari data zat cair yang melewati flow sensor untuk volume 1 liter, maka didapat hasil sebagai berikut.

Tabel 4 Pembacaan hasil analisa

\begin{tabular}{|c|c|c|c|c|c|}
\hline $\begin{array}{c}\text { Pengu } \\
\text { jian } \\
\text { Ke- }\end{array}$ & $\begin{array}{c}\text { Freku } \\
\text { ensi } \\
(\mathrm{Hz})\end{array}$ & $\begin{array}{c}\text { Pembaca } \\
\text { an flow } \\
\text { sensor } \\
\text { (Liter/me } \\
\text { nit) }\end{array}$ & $\begin{array}{c}\text { Waktu } \\
\text { pengisian } \\
\text { mengguna } \\
\text { kan flow } \\
\text { sensor (S) }\end{array}$ & $\begin{array}{c}\text { Waktu } \\
\text { pengisian } \\
\text { tanpa flow } \\
\text { sensor (S) }\end{array}$ & $\begin{array}{c}\text { Error } \\
(\mathrm{S})\end{array}$ \\
\hline 1 & 31,5 & 4,2 & 14,2 & 14,3 & 0,1 \\
\hline 2 & 32 & 4,26 & 14 & 14,3 & 0,3 \\
\hline 3 & 31 & 4,13 & 14,5 & 14,7 & 0,2 \\
\hline 4 & 32 & 4,26 & 14 & 15 & 1 \\
\hline 5 & 32,5 & 4,3 & 13,95 & 13,95 & - \\
\hline \multicolumn{7}{|c|}{ Total Error } & 1,6 \\
\hline
\end{tabular}

Keakuratan flow sensor sudah optimal, karena dari 5 kali percobaan, rata-rata error yang didapat hanya 1,6 detik untuk volume 1 liter bensin. Untuk bahan bakar bensin yang melewati flow sensor dengan volume 1 liter.

\section{SIMPULAN}

Dari penelitian ini dapat ditarik kesimpulan, bahwa: 1. Tegangan dadal IC regulator 7805 pada beberapa pengujian mendapatkan rata-rata tegangan dadalnya $6,76 \mathrm{~V}$, maka pada power supply tidak ada masalah.

2. Dalam pembuatan alat yang menggunakan rangkaian elektronik perlu memperhatikan masukkan catu daya yang stabil, yaitu dengan tegangan berkisar antara 4,5 V sampai dengan 5,5 V untuk mikrokontroler dan flow sensor, serta tegangan $3 \mathrm{~V}$ hingga $4 \mathrm{~V}$ untuk pompa motor. Alat pengisian bensin yang telah dibuat ini memiliki tegangan catu daya sebesar 4,6 V untuk mikrokontroler dan flow sensor, sedangkan untuk pompa motornya sendiri memiliki tegangan sebesar 3,23 V.

3. Rata-rata frekuensi dari flow sensor yang menggunakan pompa galon adalah sebesar $31,8 \mathrm{~Hz}$, sebagai patokan untuk mencari banyaknya volume zat cair yang melewati flow sensor.

4. Dimana keakuratan flow sensor sudah optimal, karena dari 5 kali percobaan untuk volume 1 liter bensin maka rata-rata error yang didapat hanya 1,6 detik.

5. Kecepatan pengisian bensin tergantung dengan pompa yang digunakan, karena semakin cepat 
laju pompa, maka akan membuat frekuensinya naik. Hal inilah yang mengakibatkan laju kecepatan pengisian naik pula.

\section{KEPUSTAKAAN}

[1] Guntara, F, dan Wildian, Rancang Bangun Prototipe SPBU-Mini Berbasis Mikrokontroler ATMega8535 Dengan Keluaran Berdasarkan Nilai Masukan Dalam Rupiah, Jurnal Fisika Unand. Vol. 4, No. 1. (2015)

[2] Baharuddin, Perancangan Simulasi Kontrol Otomatis Distribusi Bahan Bakar Tangki Harian Pada KM. Madani Nusantara, Jurnal Riset dan Teknologi Kelautan (JRTK), Vol. 14, No. 1. (2016)

[3] Permatasari, S.R, Helmi, dan Perdana, H, Sistem Antrian Pengisian Bahan Bakar Sepedah Motor Pada SPBU PT. Fikri Darmawan Kabupaten Melawi, Buletin Ilmiah Math. Stat. dan Terapannya (Bimaster), Vol 6, No. 02, 121-130. (2017)

[4] Alfian, Y.F, Mukhsin, M, dan Qustoniah, A, Prototype Sistem Pembelian Bahan Bakar Minyak Menggunakan RFID, Jurnal Widya Teknika, Vol. 26, No. 2, 247-259. (2018)

[5] Suhadi, Ramdani, dan Ahmad, T.Y, Rancang Bangun Alat Ukur Pengisian Bahan Bakar Minyak (BBM) Berbasis Arduino Uno Menggunakan Liquid Crystal Display (LCD), Jurnal Gerbang, Vol. 9, No.1. (2019)

[6] Rumalutur, S, Alimuddin, dan Sianipar, E.P, Sistem Kontrol Otomatis Pengisian Tangki BBM Dan Monitoring Suhu Menggunakan PLC, Jurnal Elektro Luceat Vol. 6 No. 1. (2020) 